\title{
РОЛЬ НАЛОГОВОГО МЕХАНИЗМА В ФОРМИРОВАНИИ ДОХОДОВ БЮДЖЕТА ОРЕНБУРГСКОЙ ОБЛАСТИ
}

\author{
(c) 2020 Коновалов Вадим Николаевич \\ аспирант \\ Самарский государственный экономический университет, Россия, Самара \\ E-mail:vnkonovalov@tksts.com
}

В статье рассмотрены особенности использования в налоговой практике инструментов администрирования, помогающих реализовать основные задачи деятельности налоговых органов, связанной с формированием регионального консолидированного бюджета при помощи налоговых доходов. Успешное выполнение этих задач повышает уровень экономической безопасности региона.

Ключевые слова: налоговый механизм, консолидированный бюджет, федеральный бюджет, налоговые доходы, налоговое администрирование, экономическая безопасность, налог на прибыль, налогоплательщик.

Необходимость решения задач по социальноэкономическому развитию регионов РФ тесно связана с проблемами их обеспеченности из бюджетных средств. Ключевая роль в формировании бюджетных доходов принадлежит сборам и налогам, и налоговые администрации отвечают за законность и своевременность данных перечислений. Такое положение сопряжено с немалым количеством проблем методологического и организационного характера. От того, насколько эффективно они будут решаться, зависит правильность развития налоговых отношений, которое обеспечит безопасное и устойчивое развитие экономической сферы региона.

Экономическая безопасность, представляющая собой состояние «защищенности национальной экономики от внешних и внутренних угроз» [1], дает возможность спроектировать все ее основные компоненты с национального на региональный уровень, выявлять вероятные угрозы и определяющие их факторы, определять экономические интересы для каждого субъекта РФ. А.В. Вихров говорит о модели экономической безопасности региона, как о системе безопасности финансово-бюджетной и системе безопасности налоговой. По нашему мнению, наиболее удачное определение налоговой безопасности из тех, что находятся в разных источниках, и применительно к региональным уровням, это «...состояние защищенности региональной экономики от угрозы недопоступления налоговых доходов в бюджет, при котором становится невозможным исполнение обязательств региональными органами власти и органами местного самоуправления по оказанию государственных услуг» [8]. Налоговые органы, функция которых заключается в контроле объема поступлений налоговых доходов в бюджет, своей деятельностью являют главное препятствие для угроз налоговой безопасности. Это дает возможность принимать реализуемые методики и формы налогового администрирования в роли налоговых инструментов для обеспечения экономической безопасности, установленной в регионах Российской Федерации.

В 2019 году за первые 10 месяцев в консолидированные бюджеты всех регионов РФ поступили налоговые отчисления в размере 8458,8 миллиардов рублей. Это на $8,8 \%$ больше, чем за тот же период 2018 года (табл. 1) [12]. Разумеется, не каждый субъект РФ имеет высокую степень динамики налоговых сборов в консолидированный российский бюджет; кроме того, наблюдается существенная разница уровней показателей в составе поступлений в бюджет субъекта РФ и в федеральный бюджет.

В Оренбургской области, согласно анализу структуры поступлений ключевых администрируемых налоговых доходов за указанный ранее период 2019 года, можно сделать вывод о более эффективной работе налоговых органов в плане сборов налоговых доходов и их перечислению в федеральный бюджет, по сравнению с доходами в консолидированный бюджет субъекта $(111,6 \%$ против 105,0\%).

В таблице 2 приведены данные, наглядно демонстрирующие тот факт, что наибольшую роль в образовании бюджета играют: налог на при- 
Таблица 1. Налоговые поступления в консолидированные бюджеты субъектов РФ

\begin{tabular}{|c|c|c|c|c|c|}
\hline \multirow[b]{2}{*}{ Виды налогов } & \multicolumn{2}{|c|}{ Январь-октябрь 2018} & \multicolumn{3}{|c|}{ Январь-октябрь 2019} \\
\hline & млрд. руб. & $\begin{array}{c}\text { в \% к объему } \\
\text { поступлений } \\
\text { в консолид. } \\
\text { бюджеты } \\
\text { субъектов РФ }\end{array}$ & млрд. руб. & $\begin{array}{c}\text { в \% к объему } \\
\text { поступлений } \\
\text { в консолид. } \\
\text { бюджеты } \\
\text { субъектов РФ. }\end{array}$ & $\begin{array}{c}\text { в \% к соотв. } \\
\text { периоду } 2018\end{array}$ \\
\hline Всего поступило & 7774,1 & 100,0 & 8458,8 & 100,0 & 108,8 \\
\hline Налог на прибыль & 2659,2 & 34,2 & 2956,0 & 34,9 & 111,2 \\
\hline НДФЛ & 2847,6 & 36,6 & 3088,1 & 36,5 & 108,4 \\
\hline Акцизы & 519,9 & 6,7 & 621,5 & 7,3 & 119,5 \\
\hline $\begin{array}{l}\text { Налог на имущество } \\
\text { физических лиц }\end{array}$ & 25,5 & 0,3 & 30,8 & 0,4 & 120,7 \\
\hline $\begin{array}{l}\text { Налог на имущество } \\
\text { организаций }\end{array}$ & 918,2 & 11,8 & 864,5 & 10,2 & 94,1 \\
\hline Транспортный налог & 89,0 & 1,1 & 100,0 & 1,2 & 112,4 \\
\hline Земельный налог & 147,2 & 1,9 & 147,6 & 1,7 & 100,3 \\
\hline НДПИ & 55,8 & 0,7 & 67,7 & 0,8 & 121,4 \\
\hline Другие налоги и сборы & 511,7 & 6,6 & 582,7 & 6,9 & 113,9 \\
\hline
\end{tabular}

Источник: Сайт Федеральной налоговой службы. - [Электронный ресурс].- Режим доступа: http://analytic.nalog.ru/portal/ index.ru-RU.htm - 01.03.2020.

Таблица 2. Поступление основных администрируемых доходов Оренбургской области за 10 месяцев 2019 года

\begin{tabular}{|c|c|c|c|c|c|c|}
\hline \multirow{3}{*}{ Доходы } & \multicolumn{2}{|c|}{$\begin{array}{c}\text { консолидированный } \\
\text { бюджет РФ }\end{array}$} & \multicolumn{4}{|c|}{ в том числе: } \\
\hline & \multirow[b]{2}{*}{ млрд. руб. } & \multirow{2}{*}{$\begin{array}{c}\text { в \% к соотв. } \\
\text { периоду } \\
\text { предыдущ. } \\
\text { года }\end{array}$} & \multicolumn{2}{|c|}{ федеральный бюджет } & \multicolumn{2}{|c|}{$\begin{array}{c}\text { консолидированный } \\
\text { бюджет }\end{array}$} \\
\hline & & & млрд. руб. & $\begin{array}{c}\text { в \% к соотв. } \\
\text { периоду } \\
\text { предыдущ. } \\
\text { года }\end{array}$ & млрд. руб. & $\begin{array}{c}\text { в \% к соотв. } \\
\text { периоду } \\
\text { предыдущ. } \\
\text { года }\end{array}$ \\
\hline Всего поступило & 340,3 & 110,1 & 268,9 & 111,6 & 71,3 & 105,0 \\
\hline Налог на прибыль & 33,9 & 105,8 & 4,4 & 105,7 & 29,5 & 105,8 \\
\hline НДФЛ & 22,8 & 103,4 & $\mathrm{x}$ & $\mathrm{x}$ & 22,8 & 103,4 \\
\hline НДС & 65,1 & 126,0 & 65,1 & 126,0 & $\mathrm{x}$ & $\mathrm{x}$ \\
\hline Акцизы & 3,2 & 180,3 & 1,0 & 155,7 & 2,1 & 195,2 \\
\hline $\begin{array}{l}\text { Налог на имущество } \\
\text { физических лиц }\end{array}$ & 0,1 & 85,0 & $\mathrm{x}$ & $\mathrm{x}$ & 0,1 & 85,0 \\
\hline $\begin{array}{l}\text { Налог на имущество } \\
\text { организаций }\end{array}$ & 10,4 & 96,5 & $\mathrm{x}$ & $\mathrm{x}$ & 10,3 & 96,5 \\
\hline Транспортный налог & 0,7 & 101,4 & $\mathrm{x}$ & $\mathrm{x}$ & 0,7 & 101,4 \\
\hline Земельный налог & 1,1 & 100,4 & $\mathrm{x}$ & $\mathrm{x}$ & 1,1 & 100,4 \\
\hline НДПИ & 198,1 & 107,6 & 197,4 & 107,7 & 0,7 & 102,2 \\
\hline Другие налоги и сборы & 4,7 & 104,9 & 0,9 & 88,5 & 3,8 & 109,9 \\
\hline
\end{tabular}

Источник: Сайт Федеральной налоговой службы. - [Электронный ресурс].- Режим доступа: http://analytic.nalog.ru/portal/ index.ru-RU.htm - 01.03.2020. 
быль организаций $(41,4 \%$ в общей сумме налоговых поступлений в консолидированный бюджет Оренбургской области), НДФЛ (32,0\%), налог на имущество организаций (14,6\%). Все вместе перечисленные сборы дают $88 \%$ от всех налоговых поступлений в консолидированный бюджет области [12].

Методики и формы деятельности налоговых администраций направлены на стабилизацию и расширение налоговых баз относительно налогов, администрируемых в регионе, а также совершенствование способов и путей налогового мониторинга и контроля, нормализация процесса взаимодействия с налогоплательщиками. И это далеко не весь арсенал инструментов, используемых для мотивации налогообложения, противодействия угрозам безопасности и стабилизации развития экономики региона. Таким образом, обеспечение налоговой безопасности считается одним из главных факторов, учитываемых в общей экономической безопасности.

Способы и методы, которые входят в совокупность процесса налогового администрирования и применения налоговых инструментов:

- работа по контролю в налоговых органах;

- прогнозирование и планирование;

- налоговое регулирование;

- налоговый мониторинг и аналитика;

- взаимодействие с налогоплательщиками, которое включает в себя постановку или снятие с учета, информирование, регистрацию, прием отчетной документации, а также прочие услуги, оказываемые налоговыми органами налогоплательщикам.

В состав каждой из групп налоговых инструментов входят те, которые помогают в решении тех или иных установленных задач в пределах ключевых направлений государственной налоговой политики и стратегии развития и усовершенствования определенного субъекта РФ.

Федеральная налоговая служба России имеет официальный статус «главный администратор доходов консолидированного бюджета Российской Федерации». Приведем пример того, как реализовываются ее полномочия по группе инструментов «налоговое планирование и прогнозирование».

Согласно приказу Федеральной налоговой службы от 18 июля 2018 г. № MMB-7-1/457@ «Об утверждении Методики прогнозирования поступлений доходов в консолидированный бюджет Российской Федерации на очередной финансовый год и плановый период» [11], при расчете параметров доходности консолидированного бюджета РФ предусмотрено несколько методов прогнозирования (рис.1).

Из короткого описания перечисленных методов можно сделать вывод о том, что для про-

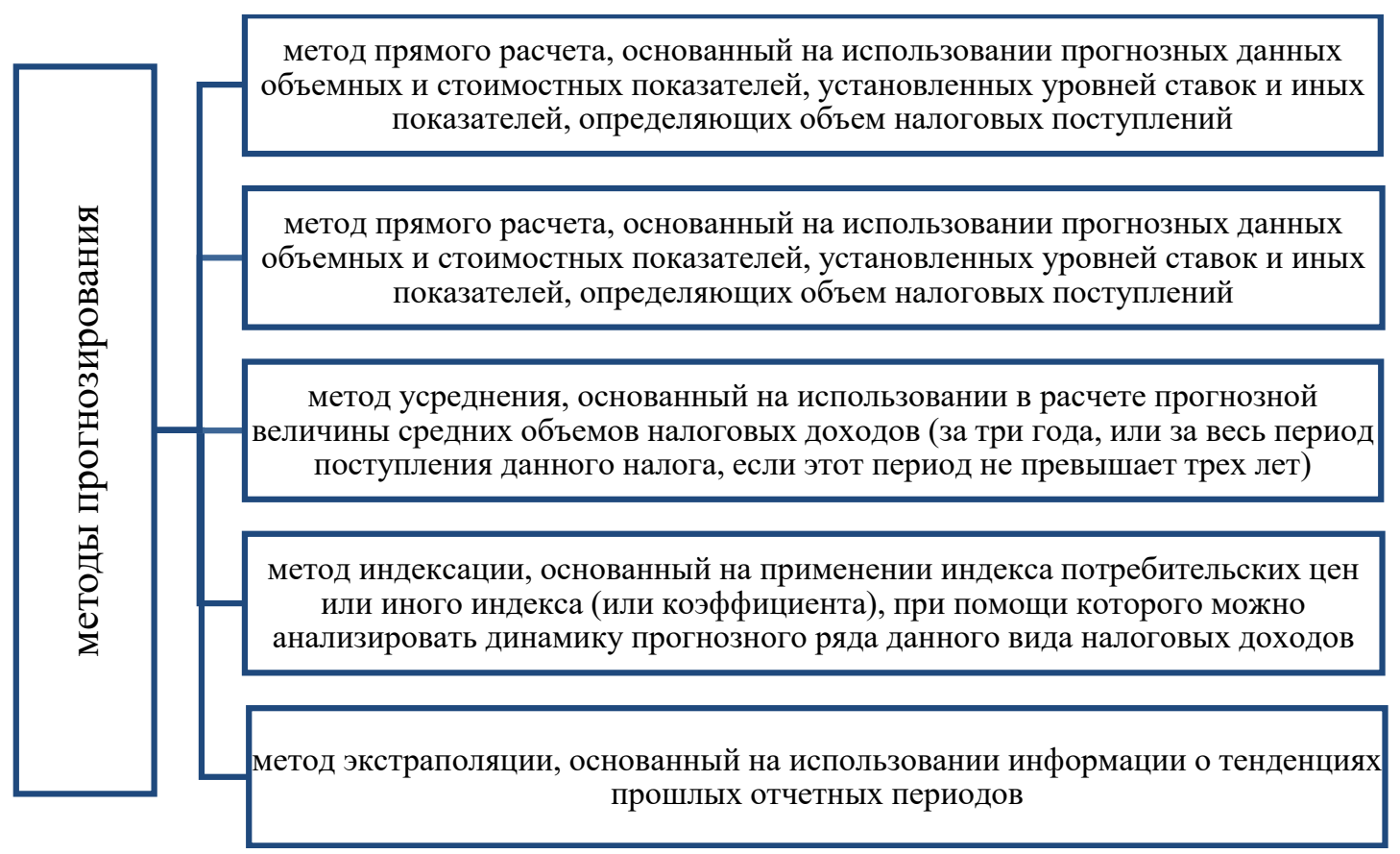

Рис.1. Методы прогнозирования поступления доходов в консолидированный бюджет Российской Федерации 
гнозирования бюджетных доходов активно применяются макроэкономические прогнозные данные, касающиеся всех направлений экономического и социального развития государства.

Основные информационные источники, позволяющие сделать прогноз количества налоговых поступлений в консолидированный бюджет России - это данные государственной статистики; аналитические сведения из налоговых органов о результатах финансово-хозяйственной деятельности компаний-налогоплательщиков; материалы, предоставленные различными ведомствами и министерствами; статистическая налоговая отчетность, в которой отражаются суммы поступлений и начислений налогов, информация о налоговых базах и структуре отчислений относительно разновидностей налогов, образовавшимся налоговым задолженностям.

В Оренбургской области прогнозирование количества налоговых поступлений на прибыль коммерческих предприятий, которое будет иметь наибольшее значение для формирования регионального бюджета, определяется на основании рассмотрения каждой из форм дохода - в совокупной сумме прогноза налога на прибыль должны учитываться все компоненты, а именно прогнозируемые объемы поступлений налога на прибыль организаций $\left(\mathrm{HП}_{\mathrm{O}}\right)$ (табл. 3).

Любой из компонентов налоговых поступлений предполагаемого налога на прибыль организаций подвергается отдельным расчетам с использованием определенной методики прогнозирования.

Ниже представлен пример расчета прогнозной величины налоговых поступлений на прибыль организаций в бюджет по определенным налоговым ставкам $\left(\mathrm{HП}_{\mathrm{O} 1}\right)$.

Расчет основывается на прямом методе.

$\mathrm{HП}_{\mathrm{O}}=\mathrm{HП}_{\text {основн. }}(+-) \mathrm{F}$

где:

$\mathrm{HП}_{\mathrm{O} 1}$ - налог на прибыль организаций, перечисляемый в бюджеты по установленным ставкам;

НП основн. - налог на прибыль организаций, перечисляемый по основной налоговой ставке;

F - корректирующая сумма перечислений, учитывающая изменения действующего налогового законодательства.

В соответствии с Методикой прогнозирования поступлений доходов в консолидированный бюджет Российской Федерации [11], налог на прибыль организаций, перечисляемый по основной налоговой ставке (НП основн.), рассчитывается по формуле:

$\mathrm{HП}_{\text {основн. }}=\left(\mathrm{VHБ}_{\text {осн. }} \times \mathrm{S}\right) \times \mathrm{K}_{\text {соб. }}+\left(\mathrm{P}_{\text {перерасчет }} \mathrm{x}\right.$ $\left.\mathrm{K}_{\text {соб. }}\right)+\mathrm{K}_{\mathrm{p}}-\mathrm{V}_{\text {льгот }}$

где:

$\mathrm{VHБ}_{\text {осн. }}$ - сумма налоговой базы для расчета налога на прибыль по основной ставке;

S - ставка налога,\%;

$\mathrm{P}_{\text {перерасчет }}$ - сумма налога, исходя их годовых перерасчетов;

\section{Таблица 3. Компоненты налоговых поступлений предполагаемого налога на прибыль организаций}

\begin{tabular}{|c|c|}
\hline Показатель & Наименование показателя \\
\hline $\mathrm{H}_{\mathrm{O} 1}$ & $\begin{array}{l}\text { суммы налога на прибыль организаций, перечисляемого в бюджеты по установленным } \\
\text { ставкам }\end{array}$ \\
\hline $\mathrm{H}_{\mathrm{O} 2}$ & $\begin{array}{l}\text { суммы налога на прибыль организаций, получаемого при выполнении Соглашении о разра- } \\
\text { ботке месторождений нефти и газа }\end{array}$ \\
\hline $\mathrm{H}_{\mathrm{O} 3}$ & $\begin{array}{l}\text { суммы налога на прибыль организаций, получаемого от доходов иностранных организаций, } \\
\text { не связанных с деятельностью в РФ, за исключением доходов, в виде дивидендов и процен- } \\
\text { тов по государственным и муниципальным ценным бумагам }\end{array}$ \\
\hline $\mathrm{H}_{\mathrm{O} 4}$ & $\begin{array}{l}\text { суммы налога на прибыль организаций, получаемого, от доходов российских организаций в } \\
\text { виде дивидендов, российскими организациями }\end{array}$ \\
\hline $\mathrm{H}_{\mathrm{O} 5}$ & $\begin{array}{l}\text { суммы налога на прибыль организаций, получаемого, от доходов российских организаций в } \\
\text { виде дивидендов, иностранными организациями }\end{array}$ \\
\hline $\mathrm{H}_{\mathrm{O} 6}$ & $\begin{array}{l}\text { суммы налога на прибыль организаций, получаемого, от доходов иностранных организаций } \\
\text { в виде дивидендов, российскими организациями }\end{array}$ \\
\hline $\mathrm{H}_{\mathrm{O}} 7$ & $\begin{array}{l}\text { суммы налога на прибыль организаций, получаемого в виде процентных доходов по госу- } \\
\text { дарственным и муниципальным ценным бумагам }\end{array}$ \\
\hline $\mathrm{H}_{\mathrm{O} 8}$ & $\begin{array}{l}\text { суммы налога на прибыль организаций, получаемого от прибыли контролируемых ино- } \\
\text { странных компаний }\end{array}$ \\
\hline НП & $\begin{array}{l}\text { суммы налога на прибыль организаций, получаемого в виде процентных доходов, полу- } \\
\text { ченных по облигациям российских организаций, за исключением облигаций иностранных } \\
\text { организаций - налоговых резидентов Российской Федерации }\end{array}$ \\
\hline
\end{tabular}


$\mathrm{K}_{\mathrm{p}}$ - сумма поступлений, определяемая по результатам проведенной контрольной работы на основании динамики показателей формы ВП «Сведения о результатах проверок налогоплательщиков по вопросам соблюдения законодательства о налогах и сборах»;

$\mathrm{V}_{\text {льгот }}-$ налог на прибыль, не поступивший в бюджет в результате предоставленных налогоплательщику льгот и преференций, предусмотренных действующим законодательством;

$\mathrm{K}_{\text {соб. }}$ - показатель собираемости налога, рассчитанный с учетом динамики собираемости предшествующих периодов.

Следует заметить, что степень собираемости рассчитывается в процентах и для подсчетов используются данные из отчета по форме № 1-НM. Этот показатель определяется путем разделения суммы полученного налога на сумму начисленного.

Существует пошаговая методика для расчета налоговой базы сборов на прибыль организаций по основной ставке $\left(\mathrm{VHБ}_{\text {осн. }}\right)$ [11]:

1. Расчет отношения «прибыли для расчета» $\mathrm{k}$ «прибыли организаций для целей бухгалтерского учета». Производится на основании показателей, полученных в предыдущих налоговых периодах. «Прибыль для расчета» при этом определяется в виде различия между «доходами от реализации» и «расходами, уменьшающими сумму доходов от реализации», и учитывает также «внереализационные доходы и расходы». Основной информационный источник для подсчетов - сведения из отчета формы № 5-П, известной как «Отчет о налоговой базе и структуре начислений по налогу на прибыль организаций».

2. Расчет суммы прибыли для налогообложения на прогнозируемые налоговые периоды (годы) без изменений полученного в предыдущем пункте соотношения.

3. Уменьшение прибыли для целей налогообложения на суммарную прибыль, не входящую в расчет при анализе налоговой базы. Необходимо отнести в уменьшение налоговой базы суммы понесенных убытков, а в увеличение налоговой базы - прибыль от действий с ценными бумагами.

Льготы и преференции, которые предоставлены в соответствии с действующим законодательством, могут повлечь за собой возникновение выпадающих доходов. Во время расчета прогнозируемого объема налоговых поступлений эти доходы необходимо учитывать в двух формах:

- в форме налоговой ставки, отличающейся от основной;

- в форме исключаемых стоимостных показателей в налоговой базе (не облагаются налогом либо облагаются по нулевой ставке).

Для того, чтобы рассчитать суммарный объем выпадающих доходов, налоговыми органами в регионах зачастую применяется алгоритм расчета предполагаемой величины объема поступлений налога на прибыль организаций, предусмотренный Методикой ФНС [11].

Из представленного примера инструмента налогового прогнозирования можно сформировать следующие выводы:

- С его использованием решается локальная задача будущего экономического развития налогоплательщика (хозяйствующего субъекта) путем расширения налоговой базы по определенной разновидности налога с помощью контроля всех возможных доходов во время расчета ее объема.

- Расширение налоговых баз представляет собой важное условие для увеличения налоговых доходов для формирования бюджета. От этого фактора зависит решение проблем, связанных с бюджетной обеспеченностью и стабильным развитием всех отраслей региональной экономики.

- Рост количества в регионе прибыльных организаций, платящих налоги - один из ключевых факторов для достижения надежного уровня развития самих компаний, конкретных отраслей и целых отраслевых комплексов, а также в общем всего региона. Не секрет, что присутствие собственных финансовых источников в форме полученной прибыли помогает созданию производственной материально-технической базы, открытию новых рабочих мест для населения, привлечению инвесторов, общему повышению качества социальной структуры региона.

Также следует учесть, что налоговый механизм в системе экономической безопасности региона показывает свою эффективность в том случае, если налоговые взаимоотношения между налогоплательщиками (компаниями, населением) основываются на взаимном доверии, а не только на страхе нарушить закон. Налогоплательщик должен понимать, что государство подвержено налоговым рискам и нельзя допустить снижения экономической защищенности региона. 


\section{Библиографический список}

1. Указ Президента Российской Федерации от 13 мая 2017 г. № 208. О стратегии экономической безопасности Российской Федерации на период до 2030 года. - [Электронный ресурс]. - Режим доступа: http://kremlin.ru/ acts/bank/41921-01.03.2020.

2. Вихров А.В. Концепция определения типологических видов экономической безопасности на региональном уровне // Инновационное развитие экономики. № 5(41). 2017. - 197-202 с.

3. Майбуров И.А. Налоговая политика. Теория и практика: учебник / И.А. Майбуров, М.Д. Абрамов, Г.А. Агарков, ред.: И.А. Майбуров.- М.: ЮНИТИ-ДАНА, 2015. - 519 с.

4. Майбуров И.А. Энциклопедия теоретических основ налогообложения / И.А. Майбуров, Ю.Б. Иванов, Е.В. Балацкий, и др.; Под ред. И.А. Майбурова, Ю.Б. Иванова.- М.: ЮНИТИ-ДАНА, 2016. - 503 с.

5. Фомин Е.П., Вихров А.В. Налоговое администрирование в РФ в современных условиях. // Проблемы развития предприятий: теория и практика: Материалы XIV Международной научно-практической конференции. СГЭУ.- 2015.- 143 с.

6. Фомин Е.П. Механизм повышения инновационного потенциала развития региона в системе стратегических векторов модернизации экономики // - СГЭУ, 2013.- 231 с.

7. Хазов Е.Н. Национальная безопасность: учебник для студентов вузов, обучающихся по специальности «Экономическая безопасность» / Е.Н. Хазов [и др.]; под ред. Н.Д. Эриашвили, О.А. Мироновой, Е.Н. Хазова.- Москва: ЮНИТИ-ДАНА, 2017.- 287 с.

8. Налоговая безопасность: монография для магистров вузов, обучающихся по направлениям подготовки «Экономика», «Юриспруденция» / [О.А. Миронова и др.]; под ред. О.А. Мироновой.- М.: ЮНИТИ-ДАНА: Закон и право, 2017. 463 с.

9. Основные направления бюджетной, налоговой и таможенно-тарифной политики на 2019 год и на плановый период 2020 и 2021 годов. [Электронный ресурс].- Режим доступа: http://www.consultant.ru/document/ cons_doc_LAW_308390/-03.03.2020.

10. Отчет о результатах экспертно-аналитического мероприятия «Анализ проблем и перспектив развития доходной базы субъектов РФ». (Утвержден Коллегией Счетной палаты РФ (протокол от 24.02.2012 г. № 9K (842), п. 7)) // Бюллетень Счетной палаты Российской Федерации № 1 (181), 2013.

11. Приказ Федеральной налоговой службы от 18 июля 2018 г. № ММВ-7-1/457@ «Об утверждении Методики прогнозирования поступлений доходов в консолидированный бюджет Российской Федерации на очередной финансовый год и плановый период».

12. Сайт Федеральной налоговой службы.- [Электронный ресурс].- Режим доступа: http://analytic.nalog.ru/ portal/index.ru-RU.htm - 01.03.2020. 